\title{
ARTICLE \\ Outcome after post-acute spinal cord specific rehabilitation: a German single center study
}

\author{
Matthias Ponfick
}

STUDY DESIGN: Retrospective cohort study.

OBJECTIVE: The objective of this study was to analyze single center outcome measures of spinal cord injury (SCI)-specific rehabilitation (SCISR) in Germany.

SETTING: The study was conducted at an SCl specialized rehabilitation center.

METHODS: Nonparametric tests for outcome description such as SCIM and length of stay. Logistic regression for outcome prediction was used.

RESULTS: One hundred and sixty patients (113 men, 47 women) with a mean age of 64.4 years were included. Non-traumatic etiologies, such as vascular diseases, tumors, infections or degenerative diseases accounted for $55.6 \%$ of SCl (89/160). Men experienced significantly more cervical lesions $(P=0.02)$ and presented with lower SCIMstart values $(P=0.04)$. Patients with AIS D (incomplete $\mathrm{SCI}$ ) had significantly higher SCIMstart and SCIMend ( $P<0.01$, each). Age correlated negatively with SCIMstart and SCIMend $(r=-0.21 ; P<0.05 ; r=-0.21 ; P<0.05$; respectively). The chance to reach an SCIMend $\geqslant 50$ points (milestone for starting post-primary rehabilitation) increased with every SCIM point at the beginning of rehabilitation by $12.2 \%$ (95\% $\mathrm{Cl} 7.3-17.3 \%)$ and for every day in rehabilitation by $1.4 \%(95 \% \mathrm{Cl} 0.5-2.3 \%)$. Every additional day in acute medical care, however, decreased the chance for this by $2.2 \%$ (95\% Cl -3.6 to $-0.8 \%)$.

CONCLUSIONS: This is the first study giving outcomes for post-acute SCISR in Germany. The obtained data support that even in an older cohort, early admission to SCISR after SCI and longer LOSreha increases the chance for higher independence at the end of the rehabilitation period.

Spinal Cord Series and Cases (2017) 3, 17055; doi:10.1038/scsandc.2017.55; published online 7 September 2017

\section{INTRODUCTION}

In the early 1940s, Sir Ludwig Guttmann postulated a concept of specialized therapy and nursing in spinal cord injury $(\mathrm{SCI}){ }^{1,2}$ Since then, spinal cord injury specialized rehabilitation (SCISR) was established and improved outcome in patients with $\mathrm{SCl}^{3}$ Recently, New et al. ${ }^{4}$ showed that patients with non-traumatic spinal cord injury (NTSCl) may achieve better outcomes after SCISR when compared with those treated in not specialized rehabilitation. Fromovich-Amit et al. ${ }^{5}$ compared SCl outcome after SCISR in four different countries (Denmark, Russia, Lithuania and Israel) presenting measurable differences between these countries. Length of stay (LOS) and spinal cord independence measure (SCIM) was highest in Denmark, whereas the most severe lesions leading to $\mathrm{SCl}$ were seen in the Russian center. ${ }^{5}$ In contrast to Denmark, where only two specialized centers for SCISR exist, ${ }^{6}$ Germany provides a variety of different centers $(n=28)$ providing all aspects of $\mathrm{SCl}$ treatment from acute care to rehabilitation. In general, acute care treatment and rehabilitation is paid by statutory or private health insurances, accident insurances or the social welfare. ${ }^{7}$ For further information about the German health-care system please refer to Busse and co-workers. ${ }^{8}$

SCISR facilities providing post-acute treatment without an acute care infrastructure (free-standing SCISR hospital) are scarce. ${ }^{7}$ Owing to this, data about post-acute SCIR is missing in Germany, this study intended to describe clinical and outcome parameters and to define outcome predictors in this cohort.

\section{METHODS}

Patients and investigated parameters

In a retrospective approach all inpatient $\mathrm{SCl}$ patients treated in our 17-bed spinal cord injury rehabilitation unit from January 2013 to September 2016 were included. In total, 160 patients (113 men, 47 women) were analyzed. Etiology of SCl was categorized in infectious diseases, tumor, vascular and degenerative diseases (NTSCl) as well as traumatic SCI (TSCl). Lesion level was aggregated into seven categories including $\mathrm{C} 1-\mathrm{C} 3, \mathrm{C} 4, \mathrm{C} 5, \mathrm{C} 6-\mathrm{C} 8$, T1-T6, T7-T12 and L1-L5. Severity of SCl was classified using the American Spinal Injury Association Impairment Scale (AIS) with $\mathrm{A}=$ motoric and sensory complete, $\mathrm{B}=$ motoric complete and sensory incomplete, $\mathrm{C}=$ motoric incomplete and muscle grades using the Medical Research Counsil (MRC) below 3/5 in more than one half of key muscles and $D=$ motoric incomplete with muscle grades $\geqslant 3 / 5$ in more than one half of key muscles. ${ }^{9,10}$ Furthermore, we collected data about LOS in the acute (LOSacute) and rehabilitative setting (LOSreha), destination (home, nursing home, acute hospital, another rehabilitation center and at home with nursing support) as well as mortality rates. The Spinal Cord Independence Measure III (SCIM) ranging from zero (fully dependent) to 100 (fully independent) ${ }^{11}$ was obtained weekly.

\section{Free-standing post-acute $\mathrm{SCl}$ rehabilitation in Kipfenberg}

The institution in Kipfenberg is specialized in early neurological rehabilitation (phase B) without integration in an acute care hospital. In contrast to nearly all other German SCl centers, patients transferred to our facility had to be in a clinically stable condition and necessitated no further surgeries. Moreover, other German SCl centers offer different departments mostly including neurosurgery, orthopedics, neuro-urology and internal medicine, whereas in Kipfenberg the focus was on rehabilitation. Monitoring of the 
vital parameters was established if necessary. In the case of life-threatening complications, the patients had to be discharged to an acute hospital. In general, patients experienced 200 daily therapy-minutes at six days per week, including physical and occupational therapy, wheelchair training, psychological support (if necessary) and professional nursing (total therapy time per day $>$ nursing time per day).

An SCIM score $\geqslant 50$ points and an independent bladder and bowel management as well as safe transfers were indicative that the patient could be discharged to inpatient post-primary rehabilitation phase $C$. Patients necessitating complex wound-management (VAC-therapy), intravenous medication or nutrition, tracheal cannula or mechanical ventilation were not appropriate for phase $C$ rehabilitation. The phase $C$ rehabilitation was applied at the health insurance if the patients may experience further recovery and if functional impairments (problems with difficult transfers like wheelchair-car transfer, bottom-wheelchair transfer, reduced cardiopulmonary capacity) represent a barrier for discharge at home. In our SCISR, we assume that patients with values below 50 SCIMend points may not cope with the greater efforts in the phase C (fewer nursing support). After an additional average stay of 3-6 weeks in inpatient post-primary rehabilitation phase $C$ the patient was discharged at home with or without outpatient nursing support. Hence, for logistic regression analysis an SCIM value of 50 points was assumed to be indicative of a beneficial post-acute rehabilitation result. According to this variable the study cohort was dichotomized in $<50$ and $\geqslant 50$ SCIMend points.

\section{Statistics}

Statistical analyses were performed using SPSS 19 (IBM, Armonk, NY, USA). Kolmogorov-Smirnov-test showed no normal-distribution; therefore, nonparametric tests were used for pairwise comparisons. Data are presented as group means $( \pm 1$ s.d.) and median (IQR), where applicable. Spearman rank correlations were used for correlation analyses between variables. Logistic regression analysis was used for revealing outcome predictors. The following parameters were included into a regression model (step-wise forward): age, gender, AIS, lesion's level, etiology, LOSacute, LOSreha and SCIMstart. A $P$-value $<0.05$ was considered as statistically significant. The local ethics committee (Bayerische Landesärztekammer, Munich, Germany) has approved the present study. This study was registered in the German Register Clinical Studies with the number DRKS00011150.

\section{RESULTS}

Demographic data are presented in Table 1. Distribution of lesion level is given in Figure 1. No differences between genders were found for SCIMend, AIS, etiology, LOSacute or LOSreha.

Spearman correlation showed that age was negatively associated with SCIMstart and SCIMend $(r=-0.21 ; P<0.05 ; r=-0.21$; $P<0.05$; respectively). SCIMend was negatively correlated with LOSacute $(r=-0.24 ; P<0.05)$. AIS categories were positively correlated with SCIMstart and SCIMend $(r=0.2 ; P<0.05 ; r=0.3$; $P<0.05$, respectively).

Comparisons between the different etiologies using KruskalWallis tests revealed a significant longer LOSacute for TSCI than for degenerative $\mathrm{SCl}(P<0.01)$. Moreover, $\mathrm{TSCl}$ offered significantly lower SCIMstart values than patients with tumors $(P<0.01)$. No differences were found for age, SCIMend and LOSreha.

Comparing the different AIS groups, it was found that patients with AIS D presented significantly higher SCIMstart and SCIMend values $(P<0.01$, each).

Logistic regression analyses revealed (SCIMend $<50, \geqslant 50$ points) that LOSreha and SCIMstart had a positive effect on reaching $\geqslant 50 \mathrm{SCIM}$ points. LOSacute had a negative effect on attaining this outcome. Table 2 compares patients with $\geqslant 50$ SCIMend points and $<50$ SCIMend points. Table 3 summarizes the results of step-wise logistic regression for achieving an SCIMend $\geqslant 50$ points. Forty-four patients (26.9\%) reached an $\mathrm{SCIMend} \geqslant 50$ points.

No clinical predictors for discharge modality were found. In total, 106 patients were discharged home (56 patients necessitating nursing support), $28 / 160$ (17.5\%) were transferred to a nursing home, $21 / 160(13.1 \%)$ needed transfer in acute care hospital and $5 / 160(3.1 \%)$ deceased.
Table 1. Demographic data of the total cohort $(n=160)$

\begin{tabular}{lccc}
\hline Characteristics & $\mathrm{N}=160$, mean \pm s.d. & Median & IQR \\
\hline Gender & & & \\
$\quad$ Men & 113 & & \\
Women & 47 & & \\
SCIMstart (points, range 0-100) & $18.4 \pm 11.5$ & 17 & 15 \\
SCIMend (points, range 0-100) & $35.0 \pm 22.9$ & 29 & 39 \\
Age (years, range 18-93) & $64.4 \pm 16.4$ & 68 & 21 \\
LOSacute (days, range 2-366) & $57.7 \pm 65.0$ & 28 & 57 \\
LOSreha (days, range 5-365) & $88.4 \pm 53.9$ & 74 & 63 \\
& & & \\
AIS & & & \\
A & 40 & & \\
B & 35 & & \\
C & 53 & & \\
D & 32 & \\
& & & \\
Etiology & $14(8.8 \%)$ & & \\
Vascular & $17(10.6 \%)$ & & \\
Tumor & $27(16.9 \%)$ & & \\
Degenerative & $31(19.4 \%)$ & & \\
Infection & $71(44.4 \%)$ & & \\
Trauma &
\end{tabular}

Abbreviations: AIS, American Spinal Injury Association Impairment Scale; IQR, interquartile range; LOSacute, length of stay in the acute clinic; LOSreha, LOS in rehabilitation; SCIMstart, spinal cord independence measure at admission; SCIMend, SCIM at discharge.

No significant differences between age and LOSacute were found between men and women. SCIMstart was significantly $(P=0.04)$ lower in men using Mann-Whitney $U$-test and men offered significantly more cervical lesions than women $\left(X^{2} P=0.02\right)$.

\section{DISCUSSION}

This is the first study analyzing clinical and outcome measures in German post-acute SCISR. The following novel insights were detected: (i) higher values in SCIMstart and LOSreha increase the chance for an SCIMend $\geqslant 50$ points, whereas higher values in LOSacute reduce the possibility to reach an SCIMend $\geqslant 50$ points, (ii) men experienced significantly more cervical $\mathrm{SCl}$ than women and presented lower SCIMstart values, (iii) nearly $45 \%$ of the study cohort experienced TSCl and these showed lower SCIMstart values than degenerative $\mathrm{SCls}$ and longer LOSacute values than patients with tumors and (iv) age was negatively correlated with SCIMstart and SCIMend.

\section{Comparison to other German SCl centers}

In Germany 28 centers are specialized to treat SCl. These are scattered throughout the country. Medical treatment within these centers is inhomogeneous, because only $75 \%$ of them have specialized surgical units, whereas $96 \%$ have intensive care units. $^{7,12}$ These differences make it difficult to compare the present data with other German $\mathrm{SCl}$ centers. In contrast to the USA or Australia, there is no German register, which complicates a between-country comparison of $\mathrm{SCl}$ centers. Indeed, some German centers provide their data for the European Multicenter Study of Spinal Cord Injury (EMSCI); however, these centers offer acute care for $\mathrm{SCl}$ and not solely post-acute SCISR under discussion here. ${ }^{13}$ According to this fact, it is not surprising that in a recent study intended to study health and life situation in $\mathrm{SCl}$ in Germany, the authors concluded that no reliable data were available. $^{14}$

\section{Comparison to other countries}

Owing to the lack of German comparison possibilities, the present data have to be compared with neighboring countries like the Netherlands. Osterthun and co-workers provide data for SCISR in 


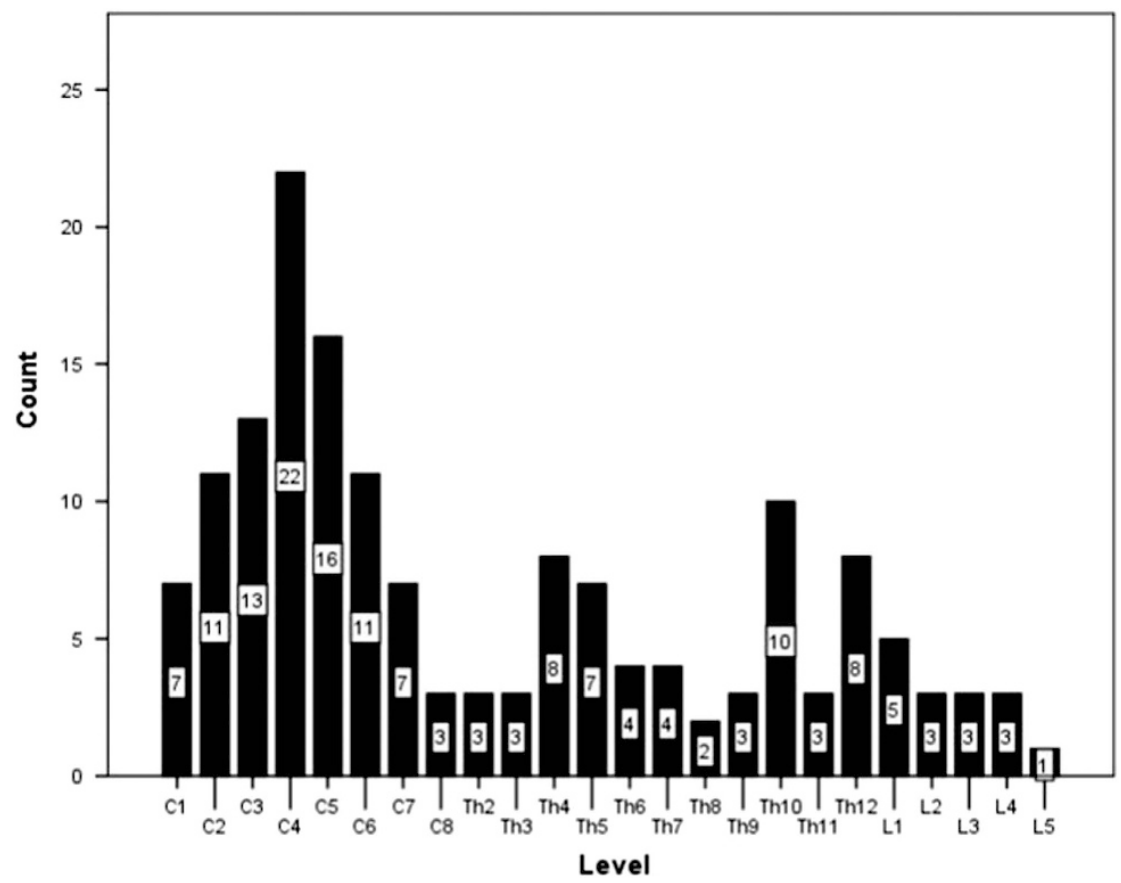

Figure 1. Distribution of lesion level $(n=160)$. Most patients presented with cervical lesions $(n=90,56.3 \%)$, followed by thoracic $(n=55$, $34.3 \%)$ and lumbar $(n=15,9.3 \%) \mathrm{SCl}$.

\begin{tabular}{|c|c|c|c|}
\hline & $\begin{array}{l}\text { SCIMend } \geqslant 50 \\
\text { points, } \mathrm{N}=44\end{array}$ & $\begin{array}{c}S C I M<50 \\
\text { points, } \mathrm{N}=116\end{array}$ & P-value \\
\hline Age (years) & 60.5 IQR 21 & 70.5 IQR 17 & 0.02 \\
\hline SCIMstart (points) & 15.0 IQR 21 & 25.5 IQR 11 & $<0.0001$ \\
\hline LOSacute (days) & 20.5 IQR 90 & 34 IQR 25 & $<0.0001$ \\
\hline LOSreha (days) & $85 \mathrm{IQR} 50$ & 74 IQR 74 & 0.32 \\
\hline Sex (male) & 32 (72.7\%) & 81 (69.8\%) & 0.85 \\
\hline Etiology & $\begin{array}{c}\text { TSCI } \\
17 / 44(38.6 \%)\end{array}$ & $\begin{array}{c}\text { TSCI } \\
54 / 116(46.6 \%)\end{array}$ & 0.63 \\
\hline Level & $\begin{array}{c}\text { C1-C8 } \\
20 / 44(45.5 \%)\end{array}$ & $\begin{array}{c}\text { C1-C8 } \\
70 / 116(60.3 \%)\end{array}$ & 0.23 \\
\hline AIS & $\begin{array}{c}\text { Motor complete } \\
\text { (A and B) } \\
15 / 44(34.1 \%)\end{array}$ & $\begin{array}{c}\text { Motor complete } \\
\text { (A and B) } \\
60 / 116(51.7 \%)\end{array}$ & 0.04 \\
\hline \multicolumn{4}{|c|}{$\begin{array}{l}\text { Abbreviations: AIS, American Spinal Injury Association Impairment Scale } \\
\text { C1-C8, cervical lesion; IQR, interquartile range; LOSacute, length of stay in } \\
\text { the acute clinic; LOSreha, LOS in rehabilitation; SCIMstart, spinal cord } \\
\text { independence measure at admission; SCIMend, SCIM at discharge; TSCI } \\
\text { traumatic spinal cord injury. } \\
\text { Significant values are in bold. For metric variables Mann-Whitney U-tes } \\
\text { and for categorical variables } X^{2} \text { test was performed. Median and IQR are } \\
\text { given due to the skewed distribution of the metric parameters. All listed } \\
\text { variables were included in the logistic regression model. }\end{array}$} \\
\hline
\end{tabular}

Flemish and Dutch centers. Their collective was distinctively younger (43.4 years for TSCl and 57.4 years for NTSCl) than the one under discussion here, but showed the very same distribution between TSCI (45.3\%) and NTSCI (54.7\%). ${ }^{15}$ A fulminant difference, however, is the LOSreha. In this study, LOSreha was on average 88.4 days, whereas in the Dutch study it was 183 days for $\mathrm{TSCl}$ and 155 days for NTSCl. ${ }^{15}$ A second Dutch study published by Vervoordeldonk et al. ${ }^{16}$ included 128 patients; $67.2 \%$ of these presented with an AIS D (NTSCI). Therefore, it is not surprising that

\begin{tabular}{|c|c|c|c|c|c|c|c|c|}
\hline & \multirow[t]{2}{*}{ B } & \multirow[t]{2}{*}{ s.e. } & \multirow[t]{2}{*}{ Wald } & \multirow[t]{2}{*}{$d f$} & \multirow[t]{2}{*}{ Sig. } & \multirow[t]{2}{*}{$\operatorname{Exp}(\mathrm{B})$} & \multicolumn{2}{|c|}{$\begin{array}{l}95 \% \text { Cl for EXP } \\
\text { (B) }\end{array}$} \\
\hline & & & & & & & Lower & Upper \\
\hline \multicolumn{9}{|l|}{ Step $1^{\mathrm{a}}$} \\
\hline SCIMstart & 0.099 & 0.020 & 25.559 & 1 & 0 & 1.104 & 1.062 & 1.147 \\
\hline Constant & -2.991 & 0.469 & 40.665 & 1 & 0 & 0.050 & & \\
\hline \multicolumn{9}{|l|}{ Step $2^{\mathrm{b}}$} \\
\hline SCIMstart & 0.092 & 0.020 & 21.896 & 1 & 0 & 1.096 & 1.055 & 1.139 \\
\hline LOSacute & -0.019 & 0.007 & 7.693 & 1 & 0.006 & 0.981 & 0.968 & 0.994 \\
\hline Constant & -2.050 & 0.513 & 15.993 & 1 & 0 & 0.129 & & \\
\hline \multicolumn{9}{|l|}{ Step $3^{c}$} \\
\hline SCIMstart & 0.115 & 0.023 & 25.826 & 1 & 0 & 1.122 & 1.073 & 1.173 \\
\hline LOSacute & -0.022 & 0.007 & 9.194 & 1 & 0.002 & 0.978 & 0.964 & 0.992 \\
\hline 3LOSreha & 0.013 & 0.004 & 8.955 & 1 & 0.003 & 1.014 & 1.005 & 1.023 \\
\hline Constant & -3.596 & 0.785 & 21.006 & 1 & 0 & 0.027 & & \\
\hline \multicolumn{9}{|c|}{$\begin{array}{l}\text { Logistic regression step-wise forward for outcome variable: SCIM } \geqslant 50 \text { and } \\
\text { SCIM }<50 \text { points. The likelihood to reach an SCIMend } \geqslant 50 \text { increases with } \\
\text { every SCIM point on admission by } 12.2 \%(95 \% \mathrm{CI} 7.3-17.3 \%) \text {. Every day } \\
\text { longer in rehabilitation elevates the possibility by } 1.4 \%(95 \% \mathrm{Cl} 0.5-2.3 \%) \text {, } \\
\text { whereas every day longer in the acute care hospital reduces the chance by } \\
2.2 \%(95 \% \mathrm{Cl}-3.6 \% \text { to }-0.8 \%) \text {. These three values explain } 81.3 \% \text { of the } \\
\text { dichotomized SCIMend. } \\
\text { a Variable(s) entered on step 1: SCIMstart. } \\
\text { b Variable(s) entered on step 2: LOSacute. } \\
\text { 'Variable(s) entered on step 3: LOSreha. }\end{array}$} \\
\hline
\end{tabular}

about $85 \%$ were discharged home, in contrast to our study where only $66 \%$ were discharged home, despite a comparable LOSreha (86.2 vs. 88.4 days). ${ }^{16}$ New et al. ${ }^{17}$ published data about SCISR in nine different countries (Australia, Canada, Italy, India, Ireland, The Netherlands, Switzerland, United Kingdom and the United States). The mean LOS was markedly lower than that in the present study (46 days vs 88 days) and over $75 \%$ of the enrolled patients 


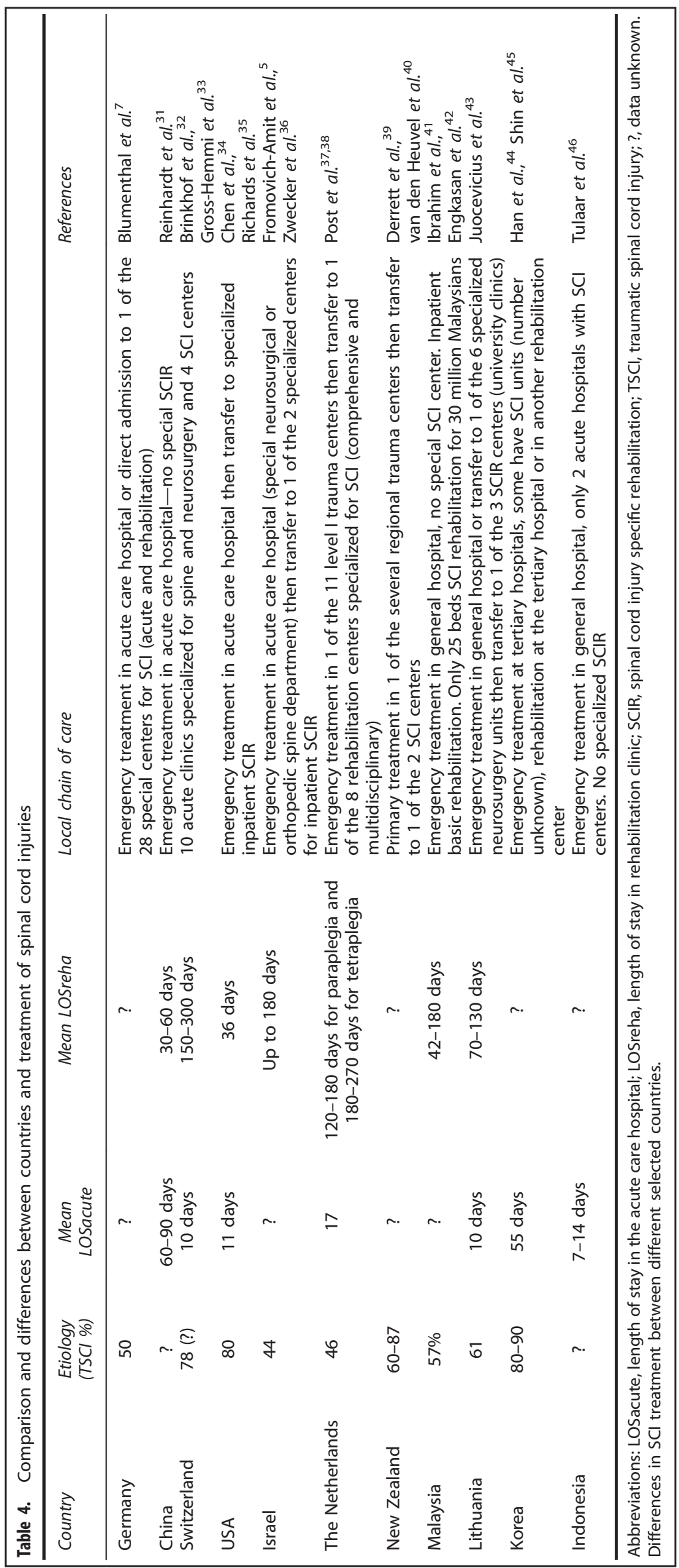


experienced motor incomplete (AIS C and D) SCl causing a rate of discharge home of $80 \% .^{17}$

When compared with the data of other non-German study cohorts, our study population is distinctively older and clinically more impaired regarding AIS and SCIM. ${ }^{16,17}$ There are several possible explanations for that. First, the health systems are not comparable between different countries. The patients' condition necessary to enter SCISR may be different from one country to another; therefore, the LOS may vary dramatically in between countries ${ }^{15}$ as does the structure of the health-care system (see Table 4).

Moreover, this study includes a selection bias. Given that our center does not provided surgical treatment, predominantly older patients with $\mathrm{NTSCl}$ and completed surgical treatment were admitted. It is well known that patients with NTSCI are older than those with TSCl. ${ }^{18}$ Furthermore, not only the patient's age but also age-associated relevant side diagnoses such as severe chronic obstructive pulmonary disease, pre-existing cerebral diseases (dementia, stroke or intracranial hemorrhage) or cardiac diseases may hamper daily independence and may reduce benefit of SCISR in that cohort. Nevertheless, this study confirms several wellknown aspects of $\mathrm{SCl}$ treatment: (i) age is associated with negative less favorable outcome, ${ }^{19-21}$ (ii) early administration to SCISR and longer stay increase the chance for higher benefits ${ }^{22-24}$ and (iii) special care in SCl significantly improves outcome. ${ }^{4,22,25-27}$

\section{Study limitations}

This study represents a retrospective approach with some immanent limitations. Important factors such as differences in bladder management, ${ }^{28}$ magnetic resonance imaging findings, ${ }^{29}$ infections during the course of rehabilitation, ${ }^{30}$ pressure sores ${ }^{30}$ or pain-all known to influence outcome-were not addressed. We found predictors for higher SCIMend scores, but not for discharge destination. The later, however, is most relevant both for patients and their relatives and for the community. In addition, rehabilitation was interrupted in about $13 \%$ of patients under investigation here. Some of them had to be discharged due to medical complications, others requested transfer to rehabilitation centers that were closer to their homes. In these cases SCIMend and LOSreha may reflect truncated values, which may influence our statistical approach. Another point of criticism may be that we defined a beneficial SCISR with $\geqslant 50$ SCIMend points. This cutoff was set to some extent arbitrarily and just relied on our experiences but not on evidences from the literature. Other clinics may use other cutoffs, above which they plan transferring a patient in the next rehabilitation phase. Therefore, our data are not irrespectively applicable for other $\mathrm{SCl}$ centers. Here, we urgently necessitate evidence-based values generated by national studies.

\section{CONCLUSION}

Despite the shortcomings mentioned above, this is the first study revealing outcome and clinical characteristics from a German post-acute SCISR center. This study underpins the benefit of SCISR even in an older cohort. Nevertheless, a multicenter approach is urgently needed to provide a better picture of SCISR in Germany.

\section{ACKNOWLEDGEMENTS}

I thank Prof Dr Nowak for his support on this work. This study was registered in the German Register Clinical Studies with the number DRKS0001115D0.

\section{COMPETING INTERESTS}

The authors declare no conflict of interest.

\section{PUBLISHER'S NOTE}

Springer Nature remains neutral with regard to jurisdictional claims in published maps and institutional affiliations.

\section{REFERENCES}

1 Guttmann L. Rehabilitation after injuries to the spinal cord and cauda equina. $\mathrm{Br} J$ Phys Med 1946; 9: 162-171.

2 Guttmann L. Nursing problems in the rehabilitation of spinal cord injuries. Nursing Times 1946; 42: 798.

3 DeVivo MJ. Sir Ludwig Guttmann Lecture: trends in spinal cord injury rehabilitation outcomes from model systems in the United States: 1973-2006. Spinal Cord 2007; 45: 713-721.

4 New PW, Simmonds F, Stevermuer T. Comparison of patients managed in specialised spinal rehabilitation units with those managed in non-specialised rehabilitation units. Spinal Cord 2011; 49: 909-916.

5 Fromovich-Amit Y, Biering-Sorensen F, Baskov V, Juocevicius A, Hansen HV, Gelernter I et al. Properties and outcomes of spinal rehabilitation units in four countries. Spinal Cord 2009; 47: 597-603.

6 Biering-Sorensen E, Pedersen V, Clausen S. Epidemiology of spinal cord lesions in Denmark. Paraplegia 1990; 28: 105-118.

7 Blumenthal M, Geng V, Egen C, Gutenbrunner C. People with spinal cord injury in Germany. Am J Phys Med Rehabil 2017; 96: S66-S70.

8 Busse R, Blümel M. Germany - Health System Review. Health Syst. Transit. 2014; 16: $1-331$

9 Marino RJ, Barros T, Biering-Sorensen F, Burns SP, Donovan WH, Graves DE et al. International standards for neurological classification of spinal cord injury. J Spinal Cord Med 2003; 26(Suppl 1): S50-S56.

10 Medical Research Council. Aids to the Investigation of Peripheral Nerve Injuries, 2nd edn. Her Majesty's Stationary Office: London, 1943.

11 Waring WP III, Biering-Sorensen F, Burns S, Donovan W, Graves D, Jha A et al. 2009 review and revisions of the international standards for the neurological classification of spinal cord injury. J Spinal Cord Med 2010; 33: 346-352.

12 Deutschsprachige Medizinische Gesellschaft für Paraplegie (DMGP). Available at http://www.dmgp.de/index.php/behandlungszentren/deutschland. Accessed on 3 June 2017.

13 European Multicenter Study about Spinal Cord Injury (EMSCI). Available at https:// www.emsci.org/index.php/members. Accessed on 3 June 2017.

14 Blumenthal M, Geng V, Egen C, Gutenbrunner C. Spinal cord injury in Germanydata on health, medical care and life situation. Phys Med Rehab Kuror 2016; 26: 303-308.

15 Osterthun R, Post MW, van Asbeck FW. Characteristics, length of stay and functional outcome of patients with spinal cord injury in Dutch and Flemish rehabilitation centres. Spinal Cord 2009; 47: 339-344.

16 Vervoordeldonk JJ, Post MW, New P, Clin Epi M, Van Asbeck FW. Rehabilitation of patients with nontraumatic spinal cord injury in the Netherlands: etiology, length of stay, and functional outcome. Top Spinal Cord Injury Rehabil 2013; 19: 195-201.

17 New PW, Reeves RK, Smith E, Townson A, Eriks-Hoogland I, Gupta A et al. International retrospective comparison of inpatient rehabilitation for patients with spinal cord dysfunction epidemiology and clinical outcomes. Arch Phys Med Rehabil 2015; 96: 1080-1087.

18 Scivoletto G, Farchi S, Laurenza L, Molinari M. Traumatic and non-traumatic spinal cord lesions: an Italian comparison of neurological and function outcomes. Spinal Cord 2011; 49: 391-396.

19 Seel RT, Huang ME, Cifu DX, Kolakowsky-Hayner SA, McKinley WO. Age-related differences in length of stays, hospitalization costs, and outcomes for an injurymatched sample of adults with paraplegia. J Spinal Cord Med 2001; 24: 241-250.

20 Cifu DX, Huang ME, Kolakowsky-Hayner SA, Seel RT. Age, outcome, and rehabilitation costs after paraplegia caused by traumatic injury of the thoracic spinal cord, conus medullaris, and cauda equina. J Neurotrauma 1999; 16: 805-815.

21 Franceschini M, Cerrel Bazo H, Lauretani F, Agosti M, Pagliacci MC. Age influences rehabilitative outcomes in patients with spinal cord injury (SCI). Aging Clin Exp Res 2011; 23: 202-208.

22 Scivoletto G, Morganti B, Molinari M. Early versus delayed inpatient spinal cord injury rehabilitation: an Italian study. Arch Phys Med Rehabil 2005; 86: 512-516.

23 Abdul-Sattar AB. Predictors of functional outcome in patients with traumatic spinal cord injury after inpatient rehabilitation: in Saudi Arabia. Neuro Rehabil 2014; 35: 341-347.

24 Herzer K, Chen Y, Heinemann A, Gonzalez-Fernández M. Association between time to rehabilitation and outcome after traumatic spinal cord injury. Arch Phys Med Rehabil 2016; 97: 1620-1627.

25 Maharaj MM, Stanford RE, Lee BB, Mobbs RJ, Marial O, Schiller M et al. The effects of early or direct admission to a specialised spinal injury unit on outcomes after acute traumatic spinal cord injury. Spinal Cord 2016; 55: 518-524. 
26 Ploumis A, Kolli S, Patrick M, Owens M, Beris A, Marino RJ. Length of stay and medical stability for spinal cord-injured patients on admission to an inpatient rehabilitation hospital: a comparison between a model $\mathrm{SCl}$ trauma center and non-SCl trauma center. Spinal Cord 2011; 49: 411-415.

27 Middleton PM, Davies SR, Anand S, Reinten-Reynolds T, Marial O, Middleton JW. The pre-hospital epidemiology and management of spinal cord injuries in New South Wales: 2004-2008. Injury 2012; 43: 480-485.

28 Kay E, Deutsch A, Chen D, Manheim L, Rowles D. Effects of etiology on inpatient rehabilitation outcomes in 65- to 74-year-old patients with incomplete paraplegia from a nontraumatic spinal cord injury. PMR 2010; 2: 504-513.

29 Wilson JR, Grossman RG, Frankowski RF, Kiss A, Davis AM, Kulkarni AV et al. A clinical prediction model for long-term functional ouctome after traumatic spinal cord injury based on acute clinical and imaging factors. J Neurotrauma 2012; 29: 2263-2271.

30 Nair KP, Taly AB, Maheshwarappa BM, Kumar J, Murali T, Rao S. Nontraumatic spinal cord lesions: a prospective study of medical complications during inpatient rehabilitation. Spinal Cord 2005; 43: 558-564.

31 Reinhardt JD, Zheng Y, Xu G, Lu X, Yin Y, Liu S et al. People with spinal cord injury in China. Am J Phys Med Rehabil 2017; 96: S61-S65.

32 Brinkhof MW, Al-Khodairy A, Eriks-Hoogland I, Fekete C, Hinrichs T, Hund-Georgiadis $M$ et al. Health conditions in people with spinal cord injury: contemporary evidence from a population-based community survey in Switzerland. J Rehabil Med 2016; 48: 197-200.

33 Gross-Hemmi MH, Pacheco Barzallo D. People with spinal cord injury in Switzerland. Am J Phys Med Rehabil 2017; 96: S116-S119.

34 Chen Y, Tang Y, Vogel LC, Devivo MJ. Causes of spinal cord injury. Top Spinal Cord Injury Rehabil 2013; 19: 1-8.

35 Richards C, MacKenzie N, Roberts S, Escorpizo R. People with spinal cord injury in the United States. Am J Phys Med Rehabil 2017; 96: S124-S126.
36 Zwecker M, Wolff J, Shaoul T, Zeilig G, Treger L. People with spinal cord injury in Israel. Am J Phys Med Rehabil 2017; 96: S78-S79.

37 Post MW, Dallmeijer AJ, Angenot EL, van Asbeck FW, van der Woude LH. Duration and functional outcome of spinal cord injury rehabilitation in the Netherlands. J Rehabil Res Dev 2005; 42(Suppl 1): 75-85.

38 Post MW, Nooijen CF, Postma K, Dekkers J, Penninx F, van den Berg-Emons RJG et al. People with spinal cord injury in the Netherlands. Am J Phys Med Rehabil 2017; 96: S93-S95.

39 Derrett S, Beaver C, Sullivan MJ, Herbison GP, Acland R, Paul C. Traumatic and non-traumatic spinal cord impairment in New Zealand: incidence and characteristics of people admitted to spinal units. Inj Prev 2012; 18: 343-346.

40 van den Heuvel M, Jansz L, Xiong X, Singhal B. People with spinal cord injury in New Zealand. Am J Phys Med Rehabil 2017; 96: S96-S98.

41 Ibrahim A, Lee KY, Kanoo LL, Tan CH, Hamid MA, Hamedon NM et al. Epidemiology of spinal cord injury in Hospital Kuala Lumpur. Spine 2013; 38: 419-424.

42 Engkasan JP, Hasnan N, Mohd Y, Abdul Latif L. People with spinal cord injury in Malaysia. Am J Phys Med Rehabil 2017; 96: S90-S92.

43 Juocevicius A, Jamontaite LE, Adomaviciene A. People with spinal cord injury in Lithuania. Am J Phys Med Rehabil 2017; 96: S86-S89.

44 Han ZA, Lee BS, Kim W, Lee SJ, Im HJ, Kim C et al. People with Spinal Cord Injury in Korea. Am J Phys Med Rehabil 2017; 96: S83-S85.

45 Shin JC, Kim DH, Yu SJ, Yang HE, Yoon SY. Epidemiologic change of patients with spinal cord injury. Ann Rehabil Med 2013; 37: 50-56.

46 Tulaar A, Karyana M, Karunia WL, Paulus A, Tinduh D, Anestherita $F$ et al. People with spinal cord injury in Indonesia. Am J Phys Med Rehabil 2017; 96: S74-S77. 